\title{
Low Spigelian hernia in a 6-year-old boy presenting as an incarcerated inguinal hernia: a case report Efstratios Christianakis ${ }^{1}$, Nikolaos Paschalidis², Georgios Filippou², Spiros Rizos², Dimitrios Smailis² and Dimitrios Filippou*2,3
}

Address: ${ }^{1}$ Department of Pediatric Surgery, Pendeli Children's Hospital, Palaia Pendeli, Athens, Greece, ${ }^{2}$ First Department of Surgery, Piraeus General Hospital "Tzaneio", Piraeus-Athens, Greece and ${ }^{3}$ Department of Anatomy, Histology and Embryology, Nursing Faculty, University of Athens, Galatsi-Athens, Greece

Email: Efstratios Christianakis - xristianakis@in.gr; Nikolaos Paschalidis - webdocgr@hotmail.com;

Georgios Filippou - georgiosfilippoumd@hotmail.com; Spiros Rizos - srizos@otenet.gr; Dimitrios Smailis - d_smailis@yahoo.gr;

Dimitrios Filippou* - d_filippou@hotmail.com

* Corresponding author

Published: 29 January 2009

Journal of Medical Case Reports 2009, 3:34 doi:10.1186/1752-1947-3-34
Received: 19 May 2008

Accepted: 29 January 2009

This article is available from: http://www.jmedicalcasereports.com/content/3/I/34

(C) 2009 Christianakis et al; licensee BioMed Central Ltd.

This is an Open Access article distributed under the terms of the Creative Commons Attribution License (http://creativecommons.org/licenses/by/2.0), which permits unrestricted use, distribution, and reproduction in any medium, provided the original work is properly cited.

\begin{abstract}
Introduction: Lower Spigelian hernia is a very rare entity. The clinical findings are similar to those of inguinal hernias and in many cases may be misdiagnosed. In the literature, only a few references to this entity have been reported in children. To the best of our knowledge, this is the first case report of a lower Spigelian hernia in a child who presented with an acute painful scrotum.
\end{abstract}

Case presentation: We discuss the case of a 6-year-old Greek boy who presented to our emergency department complaining of severe pain in the left inguinal area and scrotum. The acute painful swelling started suddenly, without any obvious cause. The initial diagnosis was incarcerated inguinal hernia which was reduced with difficulty. Five days later, the patient still experienced mild pain during palpation and he was operated on. During the operation, a large lower Spigelian hernia was revealed and reconstructed.

Conclusion: Although Spigelian hernias are rare in children and difficult to diagnose, physicians should be aware of them and include them in the differential diagnosis.

\section{Introduction}

Lower Spigelian hernia is a rare entity in pediatric surgery, and is often misdiagnosed as an inguinal hernia [1]. Less than 50 cases have been presented in the literature, and only half of them occurred in younger children. In most of these cases, Spigelian hernias are considered congenital, although there is not enough evidence to support this suggestion [2,3]. We report a rare case of a lower Spigelian hernia in a child which presented as an incarcerated inguinal hernia.

\section{Case presentation}

A 6-year-old Greek boy presented with a painful intumescence of the left inguinal area. The child was initially referred to a general hospital where the physicians suggested that the problem was an incarcerated left inguinal hernia. The hernia was reduced with difficulty by the local surgeon and the next day, the child was referred to our hospital for further evaluation and treatment. In the physical examination, the left inguinal area appeared normal without signs of intumescence. The only findings were 
subcutaneous edema and a hematoma, probably due to the manipulations for the reduction. During palpation, the child presented with mild discomfort and pain in the left testicle without clinical evidence of testicular torsion. These symptoms persisted for 3 days and finally we decided to operate on the patient. A lower Spigelian hernia was identified during the operation. The hernia sac was found to penetrate from a small defect (with an estimated diameter of about $1.5 \mathrm{~cm}$ ) in the Spigelian fascia within Hesselbach's triangle (Figure 1).

The lower Spigelian hernia orifice is usually located in a well-defined area. The defect develops as a ring-like opening through the fibers of the transversalis fascia and the fascia of the transversalis abdominus and internal oblique abdominus muscles. Spigelian hernias usually present just lateral to the rectus muscle in the lower left quadrant.

In our patient, the hernia sac was that of a typical Spigelian hernia. The orifice diameter was about $1.5 \mathrm{~cm}$, while the sac extended up to $7 \mathrm{~cm}$ surrounded by preperitoneal fat (Figure 1). The hernia sac contained a small part of the large omentum which was reduced. Reconstruction of the hernia was performed with non-absorbable sutures. Eight years after the operation, the patient remains free of symptoms and recurrence.

\section{Discussion}

Spigelian hernias occur through a congenital or usually acquired defect of the Spigelian fascia, lateral to the rectus muscle sheath [1]. In adults, almost $90 \%$ of acquired hernias occur within the anterior superior iliac spine and the umbilicus, while the majority of congenital hernias occur at the level of the arcuate line (fold of Douglas) [1-3]. Hernias that are protruding through the Spigelian fascia within Hesselbach's triangle, caudally and medially to the inferior epigastric vessels, are called low or lower Spigelian hernias [4]. Direct inguinal hernias can also occur in this area, although in most of these cases, the hernia's orifice is difficult to identify. This is the reason why many Spigelian hernias are misdiagnosed and usually considered as direct inguinal hernias, para-inguinal hernias or hernias through the conjoined tendon $[5,6]$. The diagnosis is usually made on the basis of the location of the her-

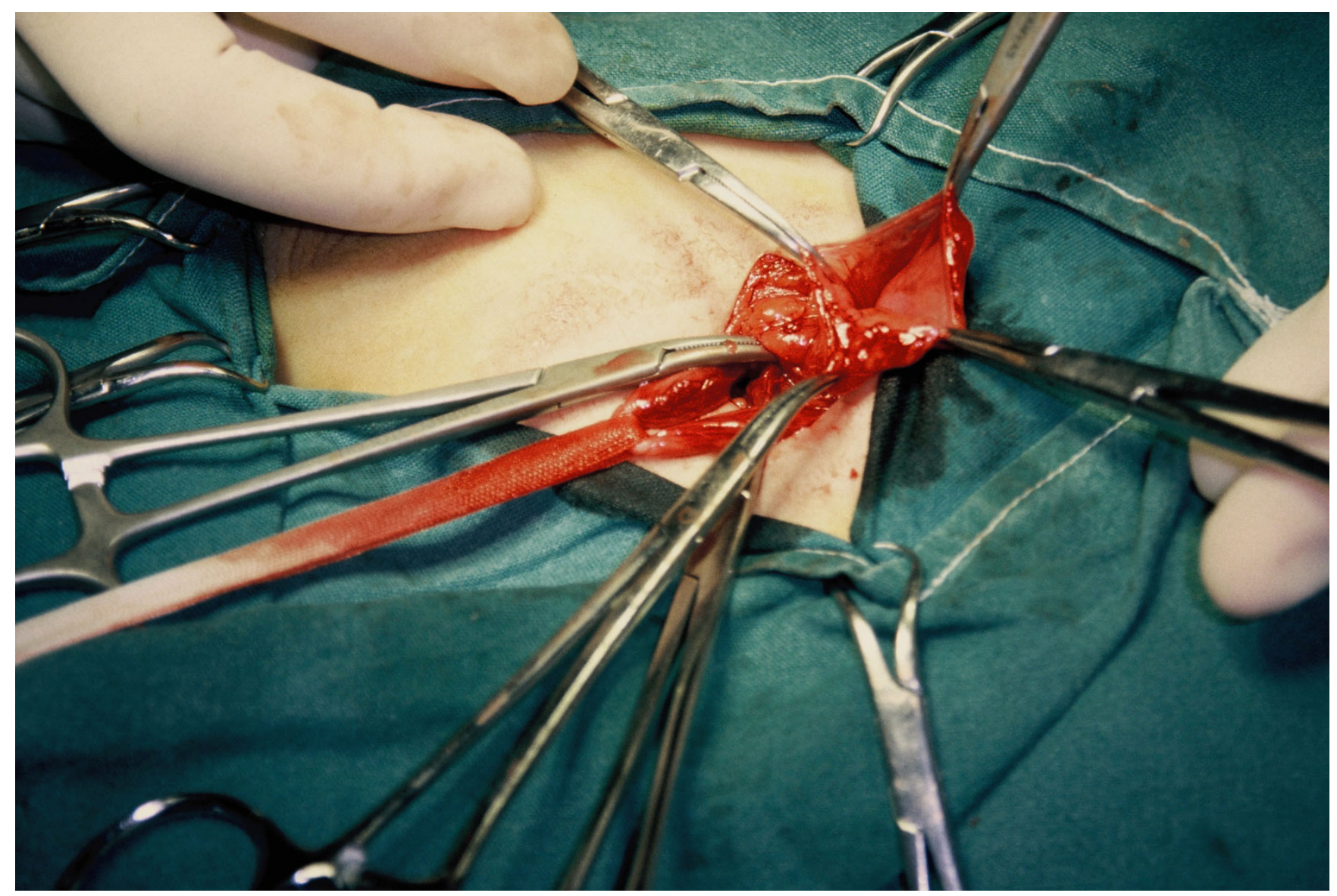

Figure I

Intra-operative photograph of the hernia showing the opened sac. 
nia's orifice. The orifice of the Spigelian hernia is usually located inside the fibers of the transversalis fascia. The orifice is sharp and rigid in palpation and its diameter ranges from 2 to $3 \mathrm{~cm}[2,3,6]$. It extends through this defect interstitially or penetrates the entire abdominal wall $[7,8]$. The sac of these hernias usually contains preperitoneal fatty tissue, and rarely omentum or intestine. Some authors have suggested that, in infants, Spigelian hernias may coexist with undescended testes.

The small size of the hernia neck may be a possible explanation for the increased incidence of incarceration. The incidence of incarceration varies significantly between various series and authors. Some authors have suggested that Spigelian hernia incarceration is a rare entity while others have suggested that it is very common with an estimated incidence of approximately $22 \%[9,10]$.

The pre-operative diagnosis of lower Spigelian hernias is difficult, especially in non-incarcerated cases. In most of the cases, diagnosis cannot be achieved by physical examination and the hernia can be easily misdiagnosed as congenital inguinal hernia. Recent studies have reported that the use of ultrasound and computed tomography (CT) may contribute to the pre-operative diagnosis in selected cases. A CT scan may be useful in the diagnosis of an incarcerated Spigelian hernia mainly due to its ability to demonstrate the layers of the anterior abdominal wall $[11,12]$.

Reduction of the content with excision of the sac and closure of the fascia defect with non-absorbable sutures is the most common and widely accepted surgical approach, presenting the lowest recurrence rates $[1,3,7]$. Recent studies support the possible role of laparoscopy in the diagnosis and treatment of Spigelian hernia in children, suggesting that it may represent an acceptable therapeutic alternative $[4,5]$.

\section{Conclusion}

Spigelian hernia occurs through a congenital or, more often, an acquired defect in the Spigelian fascia, lateral to the rectus muscle sheath. It is very rare in children. The case that we present is unique because it is probably the first report of a lower Spigelian hernia presenting as acute scrotum. No similar cases have been reported in the literature. The aim of the present case report is to alert the physician of this rare entity because, although it is difficult to diagnose pre-operatively, accurate diagnosis and appropriate treatment are essential to avoid future recurrences.

\section{Abbreviations}

SH: Spigelian hernia; CT: computed tomography.

\section{Competing interests}

The authors declare that they have no competing interests.

\section{Authors' contributions}

All authors contributed equally to the treatment of the patient (EC, NP, GF, DS, SR, DF). EC, NP and GF wrote the draft. SR and DF approved it. GF, DS and DF carried out the revision.

\section{Consent}

Written informed consent was obtained from the patient's parents for publication of this case report and any accompanying images. A copy of the written consent is available for review by the Editor-in-Chief of this journal.

\section{Acknowledgements}

The authors would like to thank Dr Stolkidis Dimitris from Korinthos General Hospital for his support in the treatment of this rare type of inguinal hernia.

\section{References}

I. Komura JL, Yano H, Uchida M, Shina I: Pediatric Spigelian hernia: reports of three cases. Surg Today 1994, 24: I08I-1084.

2. Al-Salem $\mathrm{AH}$ : Congenital spigelian hernia and cryptorchidism: cause or coincidence? Pediatr Surg Int 2000, 16:433-436.

3. White J): Concomitant spigelian and inguinal hernias in a neonate. J Pediatr Surg 2002, 37:659-660.

4. Rodgers BM, McGahren ED, Burns R: Pediatric hernias. In Abdominal Wall Hernias Edited by: Bendavid R, Abrahamson I, Arregui E, et al. New York: Springer-Verlag; 2001:59l-609.

5. Spangen L: Spigelian hernia. In Hernia Edited by: Nyhus LM, Condon RE. Philadelphia, PA: Lippincott Co; 1995:38I-392.

6. Donnellan WL: Umbilical hernias, Spigelian and other unusual abdominal hernias. In Abdominal Surgery of Infancy and Childhood Volume 2. Edited by: Donnellan WL. NY, USA: Harwood Academic Publishers; 1996:I-7.

7. Iswariah H, Metcalfe M, Morrison CP, Maddern GJ: Facilitation of open spigelian hernia repair by laparoscopic location of the hernia defect. Surg Endosc 2003, I 7:832.

8. Losanoff J, Richman B, Jones J: Spigelian hernia in a child: case report and review of the literature. Hernia 2004, 6: I91-193.

9. Kirby RM: Strangulated Spigelian hernia. Postgrad Med J 1987 , 63:51-52.

10. Spangen L: Spigelian hernia. World J Surg 1989, I 3:573-580.

II. Levy G, Nagar H, Blachar A, Ben-Sira L, Kessler A: Preoperative sonographic diagnosis of incarcerated neonatal Spigelian hernia containing the testis. Pediatr Radiol 2003, 33:307-409.

12. Toms AP, Dixon AK, Murphy JMP, Jameson NV: Illustrated review of new imaging techniques in the diagnosis of abdominal wall hernias. Br J Surg 1999, 86:1243-1249.

Publish with Bio Med Central and every scientist can read your work free of charge

"BioMed Central will be the most significant development for disseminating the results of biomedical research in our lifetime. "

Sir Paul Nurse, Cancer Research UK

Your research papers will be:

- available free of charge to the entire biomedical community

- peer reviewed and published immediately upon acceptance

- cited in PubMed and archived on PubMed Central

- yours - you keep the copyright

Submit your manuscript here:

http://www.biomedcentral.com/info/publishing_adv.asp
BiolMedcentral 